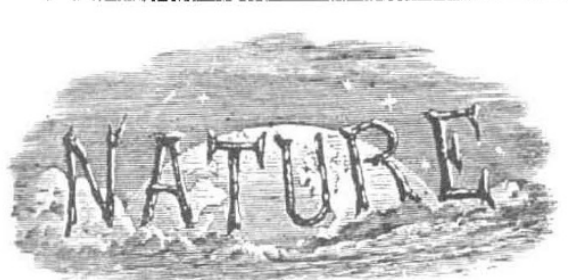

SATURDAY, APRIL 8, I933

No. 3310

Vol. 131

\title{
CONTENTS
}

Knowledge and Action

PAGE

. $\cdot 485$

De Sitter's World. By E. A. M. . . . . 487

Further Light on the Schneider Mediumship . . 489

Francis Bacon. By R. B. . . . . . 490

Short Reviews $\quad . \quad$. $\quad . \quad$. . . . $49 \mathrm{I}$

Progressive Lightning: A New Stereoscope. By

Dr. C. V. Boys, F.R.S. • • $\cdot$.

Researches on Gaseous Combustion. By Prof. W. A.

Bone, F.R.S. . . . . . . . 494

Obituary :

Prof. G. C. Bourne, F.R.S. By E. S. G. . 496

News and Views

Letters to the Editor:

Spectrum and Latitude Variation of Penetrating

Radiation.-Dr. E. J. Williams -
Absorption Spectrum of the Vitamin E Fraction

Absorption Spectrum of the Vitamin E Fraction
of Wheat-Germ Oil.-Dr. Philip Bowden and

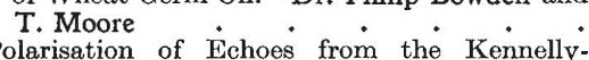

Polarisation of Echoes from the Kennelly-

Heaviside Layer.-T. L. Eckersley
Acceleration of the Decomposition of Crystals of Barium Azide by the Emission from Radium Emanation.-Prof. W. E. Garner and

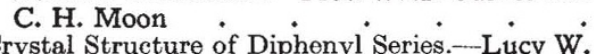

Pickett. . . .

Strange Spatfall of the Common Mussel on the Common Cockle.-Prof. J. H. Orton . .

Control of Respiratory Movements in Crustacea. -Prof. H. Munro Fox and M. L. Johnson .

'Raw' Weather.-Prof. W. A. Osborne :

Time Determination.-Dr. J. de Graaff Hunter
The Borrowed Days.-The Right Hon. Sir Herbert Maxwell, Bart., F.R.S.

Research Items.

Astronomical Topics

Population Problems in the Pacific ${ }^{\circ} \cdot 518$

Thomas Norton and the "Ordinall of Alchimy". By

Dr. E. J. Holmyard . . . . . 520

Prehistoric Society of East Anglia . . . 520

Experimental Gob Fires . . . . . 52I

Calendar of Nature Topics . . . . . . $52 \mathrm{I}$

Societies and Academies . . . . . . 522

Forthcoming Events . . . . . . . 524

Official Publications Received . . . . . 524

Supplement :

The Physical Nature of the Nerve Impulse. By Prof. A. V. Hill, O.B.E., F.R.S. . • . $50 \mathrm{r}$

Editorial and Publishing Offices:

MACMILLAN \& CO., LTD.

ST. MARTIN'S STREET, LONDON, W.C.2

Telephone Number: WHITEHALL 8831

Telegraphic Address : PHUSIS, LESQUARE, LONDON

Advertisements should be addressed to

T. G. Scott \& Son, Ltd., 63 Ludgate Hill, London, E.C. 4 Telephone Number: City 1266

\section{Knowledge and Action}

$7 \mathrm{HE}$ disproportion between poverty and unemployment and the abundance made possible by power production is leading men everywhere to question the basis of a political and economic system which permits the existence of such a paradox of maldistribution. It is no longer merely a question whether effective measures could be taken if those in authority possessed sufficient knowledge and understanding of the situation, but whether the present system permits them to take any effective action without the whole system being radically reformed. The non-success which has thus far attended the efforts or pleadings of politicians is not only fast breeding a general distrust of their policies but also a disposition to consider far-reaching changes in the structure of society.

A resolution brought forward a short time ago by Lord Melchett in the House of Lords summarises fairly concisely one such point of view :

"Since under modern scientific conditions productive capacity is unlimited, and since the existence of indigence and unemployment throughout a large portion of the population demonstrates the fact that the present monetary system is obsolete and a hindrance to the efficient production and distribution of goods, in the opinion of this House the Government should bring forward immediate proposals for the economic reforms necessary to enable the subjects of this realm to enjoy the benefits to which their present productive capacity entitles them."

The significance of this resolution lies not in its premises, which might be challenged on both sides, but in the very fact of such proposals being debated in our Second Chamber. That such a challenge to our monetary system, coupled with a plea for the national planning of industrial development, limitation of profits and evolution of a characteristic national economy modelled neither on Fascist nor Soviet lines could seriously have been made in such place would have seemed incredible but a couple of decades ago.

It is idle to ignore the fact that the ordinary citizen is beginning seriously to consider the question why politics have proved so unsuccessful where science has had such great success, and if politicians persist in asserting that a radical change cannot be produced in our existing structure of society, he will be liable to retort: "So much the worse for that structure." In a recent address to the Manchester Literary and Philosophical 
Society, Sir Ernest Simon expressed the opinion that the only way of providing a solution to our present problems is by scientific thought and by the application of reason to politics. Research into economic and political affairs on just such scientific lines as are applied to physics is essential and yet in Great Britain such research is almost non-existent. Sir Ernest also endorsed Prof. W. McDougall's plea that research on the physical sciences should largely be diverted to research on economic and political questions.

Evidence of the truth of these observations can easily be found in current affairs. The Salter Report on road and rail transport for example was rushed to a decision in July last but no definite action has yet been taken, and interests which are adversely affected are still able to maintain a barrage of criticism to the first steps which Sir Arthur Salter and his colleagues indicated as urgently required. This, of course, is a typical example of the effect of unscientific and rigid legislation which allows unforeseen situations to create forminable vested interests before they are tackled.

Similarly, the hiatus between action and knowledge in spite of all the lip service to the doctrine of national planning is well illustrated by the position of the textile industries in Lancashire. Through the activities of the Universities of Manchester and Liverpool, the Cotton Trade Statistical Bureau, the Manchester Chamber of Commerce and the various regional planning committees, Lancashire is probably the most completely surveyed area in Great Britain. Lancashire opinion has not been mobilised, however, and the chaotic condition of the cotton industry robs it of any power to influence national policy. We are still without any organisation filling the gap between the type of financial assistance supplied by the city and that required by industry to modernise its plant and improve its marketing organisation, as the chairman of the Lancashire Industrial Development Council, Mr. T. D. Barlow, has pointed out in a letter to the Prime Minister.

On the further plea for Government control and guidance of new industrial enterprise to avoid economic waste, the developments in the canning industry accentuate the need for national policy and action. The rapid erection of new canneries while the majority of those in existence are working at only half eapacity jeopardises all planned development for canning, and this new industry, which had every opportunity of starting with a clean slate and avoiding the mistakes which have handicapped the growth of other such industries, is threatened with similar loss of capital and general discouragement through low prices.

It is unnecessary to multiply examples of the imperative need of decisive Government action allied to adequate knowledge in accordance with some deliberate plea on scientific lines, though even more striking evidence could be advanced from the international sphere-disarmament, the tariff situation, Manchuria. However, it is as well to recall that the present position is not entirely novel and differs more in degree than in character from that pointed out by such an acute observer as Walter Bagehot more than half a century ago. Writing in "Physics and Politics", he notes as one mark of advancing civilisation "a diffused disposition to weigh evidence, a conviction that much may be said on every side of everything which the elder and more fanatic ages of the world wanted". To those who urged that not only did committees and parliaments fail to act with rapid decisiveness but also that no one now so acts, he replied that when we have a definite end in view, which we know we want, and which we think we know how to obtain, we can act well enough.

Bagehot's argument that the check which deliberation and discussion have placed on irrational impulse and hasty action is an untold benefit to humanity is further supported by his reminder that the impatience and excessive activity of man is one reason why science came so late into the world and is so small and scanty still in its influence. In the half-century since he wrote, however, the difficulty of relating action to knowledge has become far more acute. Not only is much more demanded of the statesman, administrator and politician, but more also is asked of the electorate. It has to be recognised that frequently public opinion, as Sir Ernest Simon pointed out, will not permit the Government to take right action. To quote a recent address by Lord Irwin: "the democratic State depends ultimately on the average judgment of its average members and it should be one of the main objects of education not to conduct mass propaganda but to win for the young the gift of right judgment in all things and the power to distinguish in public affairs and policy between the genuine coins and the spurious counterfeits".

The misgivings regarding the future of democracy which have been expressed by General Smuts, Mr. H. G. Wells and others are largely prompted by the experience of the power of democracy revealed in 
the last ten years and the danger of prejudices and passions being inflamed, amid which only the demagogue and not the statesman can gain a hearing. For the selection of the right kind of representatives in this scientific age an educated electorate is essential-informed, honest, publicspirited voters capable of electing representatives qualified by knowledge as well as by eloquence, and capable of trusting their representatives to deal with the problems and situations confronting them.

The enthronement of reason in politics outlined in Sir Arthur Salter's ideas, as in Lord Melchett's or Capt. Harold Macmillan's suggestions for an industrial parliament, involve nothing less than a revolution in democracy. While, however, there is much ground for misgivings in recent history alike in Great Britain and in the United States, there are also hopeful signs to be found of the coming of a new order.

Inadequate as the distribution of leisure at the present time may be, the extent of leisure in the modern world is growing and assuming an increasing importance in the life of each individual. The opportunities for education and for forming an intelligent opinion upon public affairs are multiplying and are being increasingly used, even if there is ample room for improvement. On the other hand, there is already an increasing disposition to experiment in our social and private lives, a sufficiently pronounced tendency to be described by Dr. C. Delisle Burns as the most important social change of the past fifty years.

This readiness to experiment is already disposing many to face the break from traditional methods or outlooks, if thereby there is any reasonable hope of redressing the balance in the present distribution of leisure and work, productive capacity and consumption. There are welcome signs of a new attitude towards science and an increasing disposition both to try new methods and to insist on the relation of administrative or executive power with full knowledge of the technical or scientific issues. The increasing efficiency of the instruments of social change is a further hopeful factor. What is in doubt is whether the progressive forces can be organised sufficiently rapidly for effective action, before the continued misuse, either in industry or in politics, of the immensely greater destructive forces released by the application of scientific discoveries, involves us in irremediable social or economic disaster. The support of scientific workers is an indispensable factor in safeguarding society, and its effective mobilisation is long overdue.

\section{De Sitter's World}

Kosmos : a Course of Six Lectures on the Development of our Insight into the Structure of the Universe, delivered for the Lowell Institute in Boston in November 1931. By Prof. W. de Sitter. Pp. xii $+138+12$ plates. (Cambridge, Mass. : Harvard University Press; London: Oxford University Press, 1932.) 9s. 6d. net.

TH HIS book affords the world an opportunity of knowing Prof. de Sitter for what his many friends have long known him to be, a great lover of science and a great lover of art. De Sitter speaks to the English-speaking peoples in a tongue which is not his own by birth, but which he uses with an unstrained eloquence that brings vivid pleasure. $\mathrm{He}$ does so by right of bis own distinguished contributions to a great subject; and he conceals his weight of technical learning under an appealing simplicity of diction. In these lectures not only astronomers and astrophysicists but also all inquirers after knowledge are shown plainly what de Sitter thinks about the world and why he thinks it worth while to go on thinking about the world. We have here no attempt to stun the reader by force of huge distances, no attempt to drug him with doses of inconceivable periods of time. The book gives the real reasons why men working at astronomical science have drawn the picture as they present it to-day.

The lectures are in form a historical account of astronomical discovery. They deal with the Ptolemaic and Copernican systems, with the great work of Kepler, Galileo and Newton, with the first ideas of the sidereal system developed by William Herschel, with Kapteyn's masterly statistical synthesis of modern observations of what we must now call the nearer stars, with a picture of the galactic system as a whole as expressed in the work of Shapley, J. S. Plaskett, Oort and others, and lastly with the great problem of the expanding universe of spiral nebulæ.

The solar system is definite enough. But the 'local cluster' and the galactic system are, one a convenient working hypothesis for certain purposes and the other a largely unknown monster. Perhaps all will not accept every detail of the picture as painted by de Sitter. It is not certain that a galactic rotation is the only legitimate interpretation of the observed double wave in the radial velocities and proper motions; the evidence 